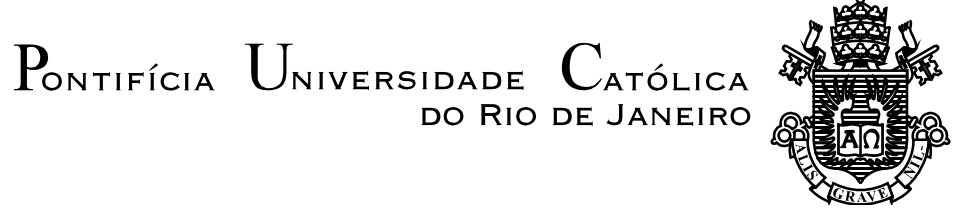

Elenir Carmen Morgenstern

\title{
ARTE E DESIGN, FRONTEIRAS EVANESCENTES?
}

\section{Tese de Doutorado}

Tese apresentada ao Programa de Pós-graduação em Design da PUC-Rio como requisito parcial para obtenção do título de Doutora em Design.

Orientador: Alberto Cipiniuk

Rio de Janeiro, fevereiro de 2011 


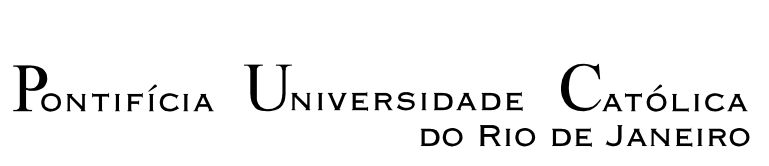

Elenir Carmen Morgenstern

Arte e Design, fronteiras evanescentes?

Tese apresentada ao Programa de Pós-graduação em Design da PUC-Rio como requisito parcial para obtenção do título de Doutora em Design. Aprovada pela Comissão examinadora abaixo assinada.

Prof. Alberto Cipiniuk

Orientador

Departamento de Artes e Design - PUC-Rio

Profa. Nadja de Carvalho Lamas

UNIVILLE

Profa. Carla da Costa Dias

UFRJ

Profa. Fernanda de Abreu Cardoso

UFRJ

Profa. Barbara Peccei Szaniecki

UERJ

Profa. Denise Berruezo Portinari

Coordenadora Setorial do Centro de Tecnologia e Ciências Humanas -

PUC-RIO

Rio de Janeiro, 24 de fevereiro de 2011. 
Todos os direitos reservados. É proibida a reprodução total ou parcial do trabalho sem autorização da universidade, da autora e do orientador.

\section{Elenir Carmen Morgenstern}

Graduou-se em Educação Artística com Habilitação em Artes Plásticas pela UNIJUÍ-RS (1994), cursou a Especialização em Metodologia do Ensino de Artes Plásticas e o Mestrado em Educação nas Ciências (2001) pela mesma instituição. Defendeu em 24 de fevereiro de 2011 sua tese de Doutorado em Design, junto ao Programa de Pós-Graduação da PUC-Rio. Tem vínculo docente com o Departamento de Design da Universidade da Região de Joinville (UNIVILLE) onde atua nas áreas de ensino, pesquisa e extensão com foco em História da Arte e Design Gráfico.

Ficha Catalográfica

Morgenstern, Elenir Carmen

Arte e Design, fronteiras evanescentes? / Elenir Carmen Morgenstern; orientador: Alberto Cipiniuk. 2011.

190 f. ; $30 \mathrm{~cm}$

Tese (doutorado)-Pontifícia Universidade Católica do Rio de Janeiro, Departamento de Artes e Design, 2011.

Inclui bibliografia

1. Artes e design - Teses. 2. Arte. 3. Design. 4. Antropologia. I. Cipiniuk, Alberto. II. Pontifícia Universidade Católica do Rio de Janeiro. Departamento de Artes e Design. III. Título. 
Porque Dele, e por meio Dele, e para Ele são todas as coisas. A Ele, pois, a glória eternamente. (Rm 11:36) 


\section{Agradecimentos}

Ao meu orientador, Dr. Alberto Cipiniuk, por me apresentar a Abordagem Social da Arte e do Design;

A UNIVILLE, pelo apoio e auxílio necessários ao desenvolvimento deste doutorado;

À CAPES, pelo apoio por meio de bolsa de estudos;

Ao meu pai Américo Morgenstern, por ter me ensinado que 'estudar é fundamental' e à minha mãe Amélia Morgenstern, por me levar a acreditar que eu era 'especialmente capaz';

As amigas Marli Everling e Luciana Barros pela revisão e palpites;

E, principalmente, aos meus amados Sidi e Helena, motivo e incentivo desse projeto e de tantos outros. 


\section{RESUMO}

Carmen Morgenstern, Elenir; Cipiniuk, Alberto. Arte e Design, fronteiras evanescentes? Rio de Janeiro, 2011. 190p. Tese de Doutorado Departamento de Artes e Design, Pontifícia Universidade Católica do Rio de Janeiro.

A intenção desta pesquisa é o entendimento teorético do design em termos estéticos (em sua forma) e extra-estéticos (como práticas sociais, analisando sua legitimação no meio social). Buscamos contribuir no processo de definição teórica para o que atualmente é nomeado pelo termo 'design gráfico', num questionamento acerca das fronteiras em que se estabelecem suas bases. Entendendo que o limite de um campo é o limite dos seus efeitos pretendemos, por meio de uma abordagem antropológica, que considere variáveis de natureza externa (questões históricas, sociais, culturais, etc.), verificar a influência da literatura artística (concernente as artes visuais), na definição teórica do campo do design (gráfico). A metodologia contempla uma análise entre a recente literatura produzida pelo campo do design, no Brasil, especialmente àquelas que dão suporte às práticas do Design Gráfico, e a literatura artística, composta pela tradição (não adentrando em escritos representativos da arte contemporânea). $\mathrm{Ou}$ seja, efetivamos um 'cruzamento' entre os artefatos literários produzidos pelos dois campos. Partimos, para isso, da seguinte premissa: grande parte das teorias contemporâneas que procuram definir o design gráfico, delineando seus principais atributos, é fundada nas teorias que, ao longo da história, deliberaram teoricamente as artes visuais, mais precisamente a 'imagem'. A relevância dos resultados da pesquisa encontra-se, principalmente, na possibilidade de auxiliar na contextualização e definição epistemológica do design, campo marcado pela diversidade de definições e, muitas vezes, teorizado de maneira pouco rigorosa.

\section{Palavras-chave}

Arte; design; antropologia. 


\section{ABSTRACT}

Carmen Morgenstern, Elenir; Cipiniuk, Alberto (Advisor). Art and Design, vanishing borders? Rio de Janeiro, 2011. 190p. Doctor Thesis Departamento de Artes e Design, Pontifícia Universidade Católica do Rio de Janeiro.

The intention of this research is the theoretical understanding of design in aesthetic terms (in its form) and extra-aesthetic ones (as social practices, analyzing it's legitimation in the social middle). We envision to contribute in the process of a theoretical definition to what's nowadays called 'graphic design', questioning the boundaries on which it has established its roots. Having realized that the limit of a field is the limit of its effects we intend, having an anthropologic approach, that considers external nature values (historic, social, cultural question, etc.), to verify the influence of the artistic literature (concerning the visual arts), on the theoretical definition of the (graphic) design field. The methodology contemplates an analysis between the recent literature produced by the design field, in Brazil, especially those which support the praxis of graphic design, and the artistic literature, composed by tradition (not entering representative reports of contemporary art). That is, we placed an "interlacement" between the literary artifacts produced by both fields. We started by the following premise: a great part of the contemporary theories that try to define graphic design, drawing its main attributes, is based on theories that, during the history, deliberated theoretically the visual arts, more precisely the 'image'. The relevance of the results of the research is, mainly, the possibility to help in the contextualization and epistemological definition of design, a field of diverse definitions and, many times, theorized on a low rigorous manner.

\section{Keywords}

Art; design; anthropology. 


\section{Sumário}

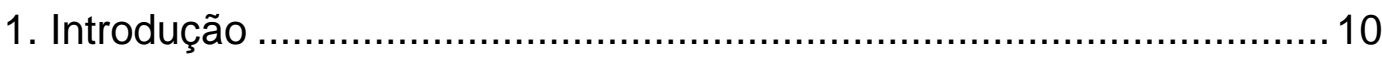

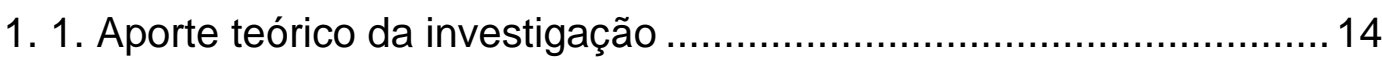

1. 2. Noções fundamentais extraídas da teoria de Bourdieu .....................16

1. 3. Conceituando arte e design....................................................... 18

1. 4. Constituição dos capítulos......................................................... 19

2. Do intertextual a relação social recíproca............................................24

2. 1. Intertextualidade: uma abordagem estruturalista ........................... 28

2. 2. Intertextualidade: homogeneidade nas abordagens........................ 36

2. 3. Da estética pura à percepção extra-estética .....................................40

2. 4. Arte e design: do intertextual à relação social recíproca ................... 46

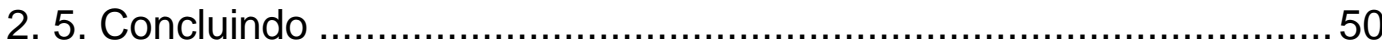

3. Abordagem antropológica do campo artístico (arte e design) ...............53

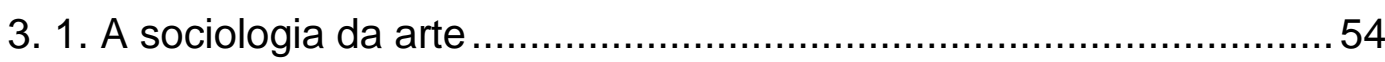

3. 2. Bourdieu e a teoria social dos sistemas simbólicos ........................57

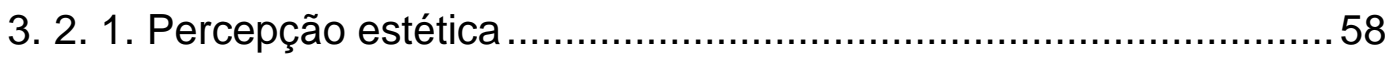

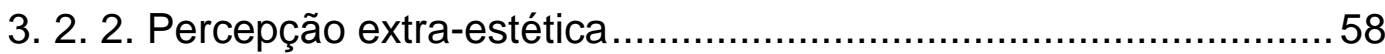

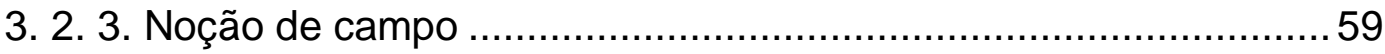

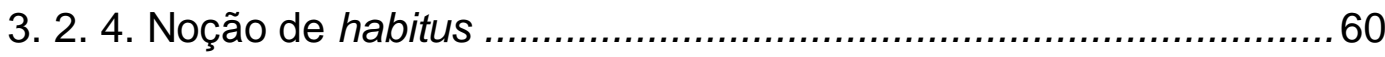

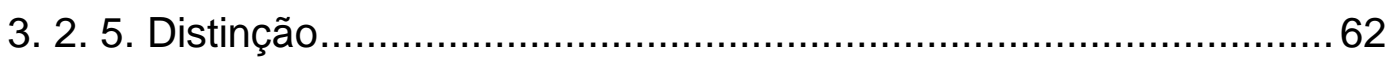

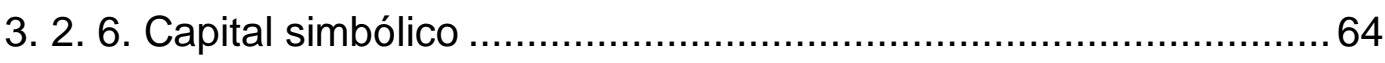

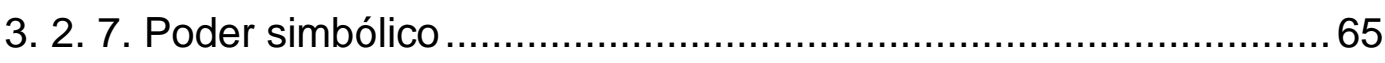

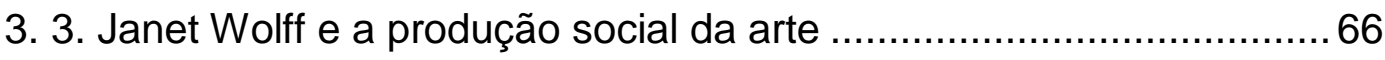

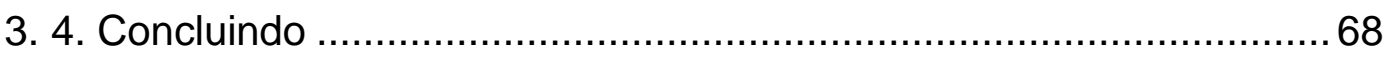


4. A literatura artística na definição do campo do design ......................... 75

4. 1. Princípios/noções fundamentais da arte e do design ....................... 80

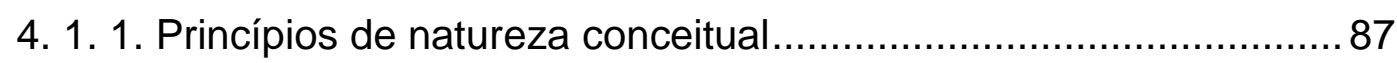

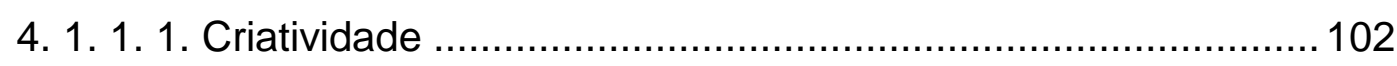

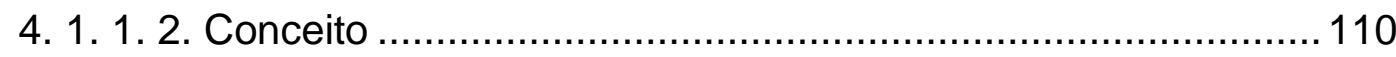

4. 1. 1. 3. Da interpretação dos objetos do campo da arte e do design . 113

4. 1. 1. 4. Da produção carismática ao conceito de Gênio ......................117

4. 1. 1. 5. Do gosto e do juízo estético .............................................. 124

4. 1. 2. Princípios fundamentais de natureza prática............................. 133

4. 1. 2. 1. Os elementos gráficos...................................................... 133

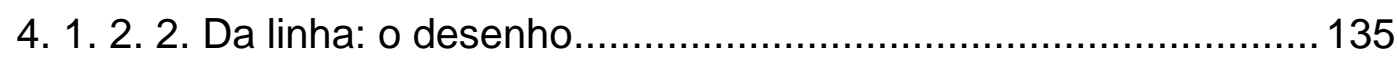

4. 1. 2. 3. Da forma ou configuração ................................................. 138

4. 1. 2. 4. Do espaço, composição e volume....................................... 142

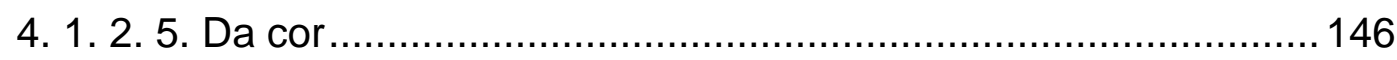

4. 1. 2. 6. Do método e da metodologia ............................................. 152

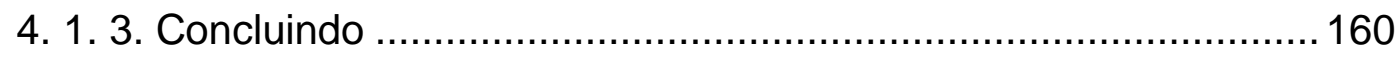

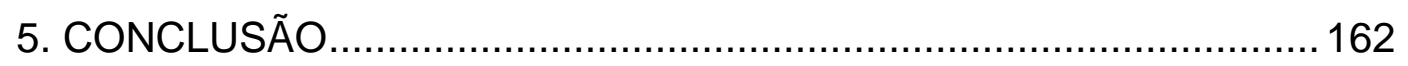

6. REFERÊNCIAS BIBLIOGRÁFICAS ............................................... 174

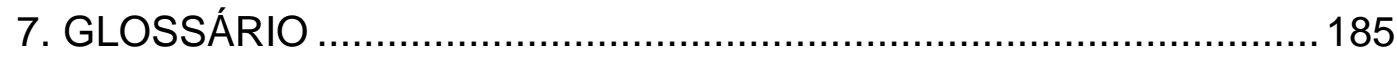

